\title{
Management of subaxial cervical instability in very young or small-for-age children using a static single-screw anterior cervical plate: indications, results, and long-term follow-up
}

\author{
Sarah T. Garber, MD, and Douglas L. Brockmeyer, MD \\ Department of Neurosurgery, Primary Children's Medical Center, University of Utah, Salt Lake City, Utah
}

\begin{abstract}
OBJECTIVE Subaxial cervical instability in very young or small-for-age children is uncommon and typically arises from trauma or skeletal dysplasia. Various operative techniques have been used to achieve stabilization in pediatric patients with evidence of instability, including anterior, posterior, and combined approaches. In this study, the authors report their results with subaxial cervical instability in this patient population treated using a static single-screw anterior cervical plate (ACP) system and allograft fusion.
\end{abstract}

METHODS In a retrospective chart review, the authors identified all patients 6 years of age or younger who underwent an anterior cervical fusion procedure using a static single-screw ACP system either as a stand-alone construct or as part of an anterior-posterior stabilization procedure. Reasons for fusion included trauma, tumor, and congenital anomalies.

RESULTS Five patients 6 years of age or younger underwent anterior cervical fusion using a static single-screw system during the 19-year study period. Follow-up ranged from 12 to 51 months (mean 26.8 months). Two patients underwent repeat surgery, one 7 days after and the other 21 months after their initial procedure. At last follow-up, a mean vertical growth of $22.8 \%$ was seen across the fused segments, with no evidence of kyphotic or lordotic abnormalities.

CONCLUSIONS In very young or small-for-age children, the use of a static single-screw ACP system appears to be a safe and effective option to manage subaxial cervical instability. Bony fusion and continued longitudinal growth occur within the fused segments, with no evidence of long-term cervical malalignment.

http://thejns.org/doi/abs/10.3171/2015.10.SPINE15537

KEY WORDS cervical; instability; anterior; pediatrics

$\mathrm{S}$ UBAXIAL (C3-7) cervical instability in children may be caused by a variety of conditions, including trauma, neoplasms, skeletal dysplasia, and congenital vertebral anomalies. Despite these varying etiologies, the underlying principles governing management of subaxial instability are the same: to provide structural support and stability to the vertebral column and spinal cord; to preserve cervical motion; and to ensure future spine growth. Applying those principles to the management of pediatric subaxial instability is particularly challenging in very young $(<6$ years) or small-for-age children. In this group, the aforementioned goals are difficult to achieve because of the patients' small size and growth potential and the lack of pediatric-specific cervical instrumentation. In patients younger than 6 years, the pediatric vertebral column does not easily accommodate adult-sized cervical instru- mentation because of the reduced radius of curvature in the young child's vertebral body as well as a very small vertebral body height-to-disc ratio. As a result of these anatomical differences, adult anterior instrumentation is a poor fit in the pediatric subaxial cervical spine. Little has been published on this technical topic, with the only mention being part of overall case reviews in the literature. ${ }^{3,4}$

Several treatment options exist for management of subaxial cervical instability in very young or small-for-age children. Depending on the nature of the instability, these options include immobilization with a hard cervical collar, halo vest placement, cervical fusion via an anterior-posterior combined approach with instrumentation, and anterior-posterior fusion with halo placement. If anterior fusion with instrumentation is chosen, 2 main options exist for anterior cervical plating-static or dynamic systems. There

ABBREVIATIONS ACDF = anterior cervical discectomy and fusion; $A C P=$ anterior cervical plate.

SUBMITTED May 8, 2015. ACCEPTED October 13, 2015.

INCLUDE WHEN CITING Published online February 19, 2016; DOI: 10.3171/2015.10.SPINE15537. 
is considerable experience with both static and dynamic anterior cervical plates (ACPs) in older pediatric patients using traditional adult-sized hardware; however, the care of patients with subaxial instability who are younger than 6 years is more problematic because of the anatomical issues described above. To address this problem, we have chosen to use a low-profile static ACP with a single screw at the cephalad end and a single screw at the caudad end (NuVasive Helix Mini ACP, NuVasive, Inc.; or Uniplate with anterior cervical plating system, DePuy Synthes) to achieve anterior cervical support. To our knowledge, the use of such an anterior cervical plating system in very young children has not been previously published. Here we report our results using this plating system in very young children with subaxial cervical instability.

\section{Methods \\ Patient Population}

After receiving institutional review board approval, we undertook a retrospective chart review to identify all children 6 years of age or younger who underwent anterior cervical arthrodesis and instrumentation at our institution between January 1, 1995, and December 31, 2014. This included children who underwent anterior cervical corpectomy or discectomy followed by placement of a static anterior cervical plating system. Clinical characteristics, indications for fusion, neurological examination findings, and the use of a cervical collar postoperatively were reviewed. Pre- and postoperative radiographs were analyzed, with emphasis on fusion status, alignment, and longitudinal cervical bone growth.

\section{Operative Technique}

The patient is intubated and placed in the supine position in gentle Halter traction. Intraoperative neuromonitoring is not routinely used. A transverse incision is planned over the appropriate level using fluoroscopic guidance. We prefer a right-sided approach because the senior author (D.L.B.) is right-handed, although a left-sided approach can be used as well. Self-retaining retractors are placed to aid in exposure. The distraction posts are placed in the superior and inferior vertebral bodies to be fused. The disc space is incised, and the discectomy is performed under the microscope. If applicable, a corpectomy is performed using a high-speed bur. Once the vertebral body endplates are smooth, a cadaveric iliac crest allograft is placed into the disc space using fluoroscopy. We prefer using cadaveric allograft to avoid a second incision to harvest autologous bone such as iliac crest. The allograft is coated with demineralized bone matrix (DBX, Medtronic Corp.), which is used for its osteoinductive properties to aid in bone fusion. Once the graft is in place, the microscope is then removed from the field and the plate is placed under fluoroscopic guidance. The holes for the distraction post and the holes for the plate are the same. This procedure is different from a conventional adult anterior cervical discectomy and fusion (ACDF) where there are 2 screws per vertebral body. The single-screw ACP system provides a single point of midline fixation per level, which allows easier screw placement and less lateral retraction. We used variable angle screws in all patients so that we would have greater flexibility with screw positioning in our pediatric patients who have smaller vertebral bodies. We did aim for bicortical screw placement for better purchase in the bone. Careful hemostasis is then obtained using bipolar electrocautery, and the platysma and subcuticular layers are reapproximated using an absorbable suture.

\section{Results}

We identified 5 patients (4 boys, 1 girl; ages 15-76 months) who underwent anterior cervical arthrodesis and instrumentation with a static single-screw ACP system at our institution during the study time period (Table 1). The indications for surgery included trauma $(\mathrm{n}=1)$, postlaminectomy kyphosis following a posterior cervical tumor resection $(\mathrm{n}=1)$, and skeletal dysplasia $(\mathrm{n}=3)$. Two patients underwent combined anterior-posterior procedures. The decision to perform a combined anterior-posterior procedure was at the discretion of the surgeon and was based on intraoperative bone quality and screw purchase during the anterior approach. All patients were placed in a custom hard cervical collar postoperatively. The most common level fused was C3-5 $(n=2)$. One patient with Klippel-Feil syndrome required a repeat surgical procedure because of fusion failure at the site of a C3-5 anterior cervical corpectomy and fusion. A second patient with postlaminectomy kyphosis after resection of a C-2 aneurysmal bone cyst required a revision 7 days after the initial surgery because he developed a proximal joint kyphosis at the level below the C2-3 ACDF. Long-term follow-up of cervical alignment (average of 26.8 months) showed no evidence of kyphotic/ lordotic abnormality or adjacent-segment pathology in the patients studied. Longitudinal bone growth across the fused segments was measured on lateral radiographs of the cervical spine using an immediate postoperative film and the most recent follow-up film according to the technique described by Anderson et al. ${ }^{1}$ This method uses the following equation to determine percentage growth: [height of the construct (follow-up - postoperative)]/[height of the cervical spine (follow-up - postoperative) $] \times 100$. Vertical growth of the cervical spine was measured from the base of the C-7 vertebral body to the basion. Vertical growth of the construct was measured from the base of the vertebral body at the lower level of the fusion to the top of the vertebral body at the upper end of the fusion construct. All measurements were performed using lateral cervical spine radiographs obtained during the immediate postoperative period and at the time of most recent follow-up. During the follow-up period, the average vertical growth across the fused segments was $22.8 \%$ (Table 1), and all 5 patients experienced continued longitudinal bone growth during the study period. There were no complications such as dysphagia, vascular injury, vocal cord paralysis, esophageal injury, or new neurological deficit in any of the patients.

\section{Illustrative Cases \\ Case 1}

A 3-year-old boy with diastrophic dysplasia showed evidence of progressive cervical kyphosis, with an acute kyphotic angulation of $63^{\circ}$. The $\mathrm{C}-4$ vertebral body was 
TABLE 1. Demographic and surgical characteristics of 5 patients who underwent fusion with a static single-screw ACP system

\begin{tabular}{|c|c|c|c|c|c|c|c|c|}
\hline $\begin{array}{l}\text { Patient } \\
\text { No. }\end{array}$ & $\begin{array}{c}\text { Age } \\
\text { (mos), } \\
\text { Sex }\end{array}$ & Pathology & $\begin{array}{l}\text { Neurologically } \\
\text { Intact } \\
\text { Preoperatively }\end{array}$ & Procedure & $\begin{array}{l}\text { Follow-Up } \\
\text { (mos) }\end{array}$ & Fusion & Revision & $\begin{array}{c}\% \\
\text { Vertical } \\
\text { Growth }\end{array}$ \\
\hline 1 & $15, \mathrm{M}$ & $\begin{array}{l}\text { Congenital C-2 pars defects w/ } \\
\text { spondylolisthesis }\end{array}$ & No & C2-3 ACDF & 51 & Yes & None & 40 \\
\hline 2 & $35, \mathrm{M}$ & $\begin{array}{l}\text { Diastrophic dysplasia w/ cervi- } \\
\text { cal kyphosis }\end{array}$ & No & $\begin{array}{l}\text { C3-5 fusion, C-4 } \\
\text { corpectomy }\end{array}$ & 17 & Yes & None & 20 \\
\hline 3 & $67, \mathrm{M}$ & Klippel-Feil syndrome & Yes & $\begin{array}{l}\text { C3-5 ACDF, Oc-C2 } \\
\quad \text { PCF }\end{array}$ & 36 & No & $\begin{array}{l}\text { C2-4 ACDF due to pro- } \\
\text { gressive kyphosis }\end{array}$ & 34 \\
\hline 4 & $59, \mathrm{~F}$ & Traumatic C6-7 perched facets & Yes & C6-7 ACDF, C6-7 PCF & 18 & Yes & None & 10 \\
\hline 5 & $76, \mathrm{M}$ & $\begin{array}{l}\text { Aneurysmal bone cyst w/ } \\
\text { postlaminectomy kyphosis }\end{array}$ & Yes & C2-3 ACDF & 12 & No & $\begin{array}{l}\text { C3-4 ACDF, C2-4 plat- } \\
\text { ing due to kyphosis }\end{array}$ & 10 \\
\hline
\end{tabular}

Oc = occiput; PCF = posterior cervical fusion.

severely hypoplastic, resulting in anterolisthesis of C-3 on C-4 with a focal cervical kyphosis and spinal canal narrowing at this level (Fig. $1 \mathrm{~A}-\mathrm{C}$ ). The patient underwent anterior C-4 corpectomy with $\mathrm{C} 3-5$ instrumentation and fusion with the aid of gentle intraoperative Halter traction. On follow-up imaging performed initially at 4 months postoperatively and then yearly thereafter, the hardware was intact with evidence of bone fusion under the plate (Fig. 1D). There was a vertical growth of $20 \%$ across the fused segments during the follow-up period.

\section{Case 2}

A 6-year-old boy underwent bilateral C-2 laminectomies for resection of an aneurysmal bone cyst that was causing posterior cervical neck pain (Fig. 2A). Postoperatively, the patient developed kyphosis at C2-3 and underwent C2-3 ACDF (Fig. 2B). Postoperative films showed that the hardware was appropriately positioned but that a significant kyphotic abnormality had developed at C3-4 (Fig. 2C). The patient returned to the operating room for removal of the plate at $\mathrm{C} 2-3$, a $\mathrm{C} 3-4$ discectomy, and placement of a plate spanning $\mathrm{C}-2$ to $\mathrm{C}-4$. The patient did well after this procedure, and follow-up imaging showed good alignment across the instrumented segments (Fig. 2D). There was a vertical growth of $10 \%$ across the fused segments during the follow-up period.

\section{Discussion}

We have described our experience in managing 5 patients 6 years of age or younger who underwent anterior cervical fusion with a single-screw system. During a 26.8-month average follow-up, all 5 patients experienced continued longitudinal bone growth across the fused segments of the subaxial cervical spine, indicating that the use of a static plate during an anterior cervical fusion procedure in the incompletely ossified pediatric cervical skeleton provides the structural support necessary for stability without compromising bone growth. ${ }^{1}$

Previous work has shown that anterior cervical instrumentation techniques provide a solid fusion in cases of traumatic or congenital instability in patients between the ages of 6 and 16 years. $^{2}$ In that study, 12 patients un- derwent anterior cervical plating with no long-term graft or fusion failures. The use of posterior cervical fusion techniques via lateral mass or pedicle screws for subaxial cervical spine fixation is also well documented in the pediatric literature; ${ }^{6,7}$ however, to the best of our knowledge, ours is the first study describing the use of anterior cervical plating using a rigid single-screw fixation system in children 6 years of age or younger.

Although either static or dynamic plates can be used for anterior cervical arthrodesis and instrumentation, in very young patients we prefer a rigid static single-screw ACP

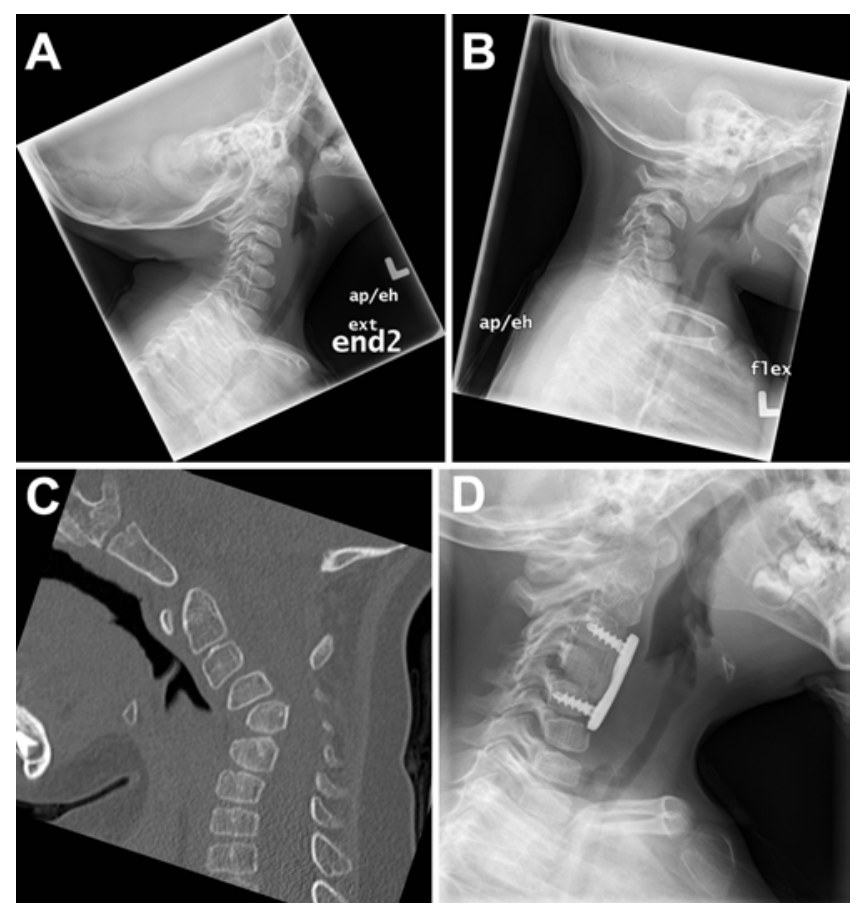

FIG. 1. Case 1. Extension (A) and flexion (B) radiographs of the cervical spine showing anterior subluxation of $\mathrm{C}-3$ onto $\mathrm{C}-4$. Sagittal noncontrast CT scan (C) of the cervical spine shows a hypoplastic C-4 vertebral body. Postoperative lateral cervical spine radiograph (D) obtained at 17-month follow-up showing bony fusion around the plate and no evidence of subsidence or hardware failure. 


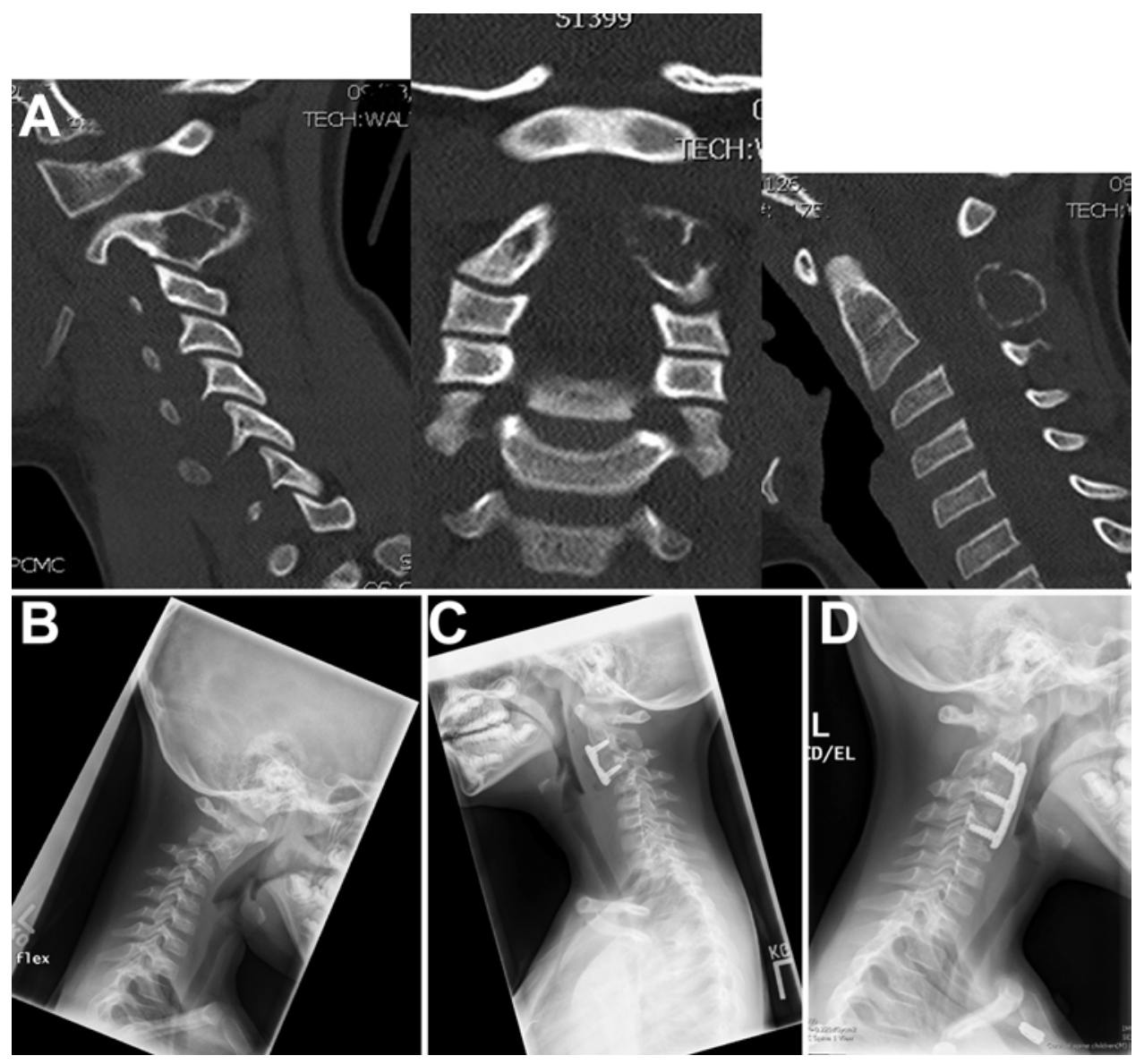

FIG. 2. Case 2. A: Sagittal (left), coronal (center), and midsagittal (right) noncontrast CT scans of the cervical spine showing an aneurysmal bone cyst involving the posterior elements of C-2. B: Lateral radiograph of the cervical spine after resection of the cyst showing kyphosis of C-2 on C-3. C: Lateral radiograph of the cervical spine after C2-3 ACDF showing appropriate hardware position but kyphosis at C3-4. D: Lateral radiograph of the cervical spine after C3-4 ACDF and removal of the C2-3 and C2-4 plates. The hardware is in good position and anatomical alignment is maintained.

system because of its more appropriate size. There is concern with static plates, however, that the increased rigidity might lead to stress on the adjacent levels and increase the risk of a pseudarthrosis..$^{5}$ In our study, 1 patient developed a pseudarthrosis requiring a repeat surgical procedure, but this was likely due to the long lever arm applied across the instrumented segment along with poor collar compliance. Overall, several studies have shown similar fusion rates between static and dynamic plating systems. ${ }^{5}$

In young children in whom the axial skeleton is still growing, we believe that strict adherence to wearing a hard cervical collar during the postoperative period is key to helping stabilize the cervical spine during the early period of bone fusion with the plate. Typically, we like to keep patients in a custom hard cervical collar until radiographic evidence of successful fusion is available, which is typically 4-6 weeks after surgery.

This study has several limitations. First, the sample size of 5 patients is small, making it difficult to generalize to a larger population of pediatric patients. Second, to avoid radiation in this young population, we obtained postoperative cervical spine radiographs instead of CT scans to determine fusion status. We believe that evidence of solid bony bridging on plain films, with or without flexion/extension images, is sufficient to determine fusion status.

\section{Conclusions}

In this study, we found that the use of a static singlescrew ACP system was a safe and effective way to manage very young or small-for-age children with subaxial cervical instability. Longitudinal growth was seen within the fused segments in all patients, with no evidence of longterm cervical malalignment. Although this work supports the continued use of static ACPs in pediatric patients with subaxial cervical instability, the very small sample size suggests that larger studies are needed to confirm these findings.

\section{Acknowledgments}

We would like to thank Kristin Kraus, MSc, for her help with the preparation of this paper.

\section{References}

1. Anderson RC, Ragel BT, Mocco J, Bohman LE, Brockmeyer 
DL: Selection of a rigid internal fixation construct for stabilization at the craniovertebral junction in pediatric patients. $\mathbf{J}$ Neurosurg 107 (1 Suppl):36-42, 2007

2. Brockmeyer D, Apfelbaum R, Tippets R, Walker M, Carey L: Pediatric cervical spine instrumentation using screw fixation. Pediatr Neurosurg 22:147-157, 1995

3. Brown RL, Brunn MA, Garcia VF: Cervical spine injuries in children: a review of 103 patients treated consecutively at a level 1 pediatric trauma center. J Pediatr Surg 36:11071114,2001

4. Eleraky MA, Theodore N, Adams M, Rekate HL, Sonntag VK: Pediatric cervical spine injuries: report of 102 cases and review of the literature. J Neurosurg 92 (1 Suppl):12-17, 2000

5. Goldberg G, Albert TJ, Vaccaro AR, Hilibrand AS, Anderson DG, Wharton N: Short-term comparison of cervical fusion with static and dynamic plating using computerized motion analysis. Spine (Phila Pa 1976) 32:E371-E375, 2007

6. Haque A, Price AV, Sklar FH, Swift DM, Weprin BE, Sacco DJ: Screw fixation of the upper cervical spine in the pediatric population. Clinical article. J Neurosurg Pediatr 3:529_ 533, 2009

7. Hwang SW, Gressot LV, Rangel-Castilla L, Whitehead WE,
Curry DJ, Bollo RJ, et al: Outcomes of instrumented fusion in the pediatric cervical spine. J Neurosurg Spine 17:397409,2012

\section{Disclosures}

The authors report no conflict of interest concerning the materials or methods used in this study or the findings specified in this paper.

\section{Author Contributions}

Conception and design: Brockmeyer. Acquisition of data: Garber. Analysis and interpretation of data: Garber. Drafting the article: both authors. Critically revising the article: Brockmeyer. Reviewed submitted version of manuscript: both authors. Approved the final version of the manuscript on behalf of both authors: Brockmeyer.

\section{Correspondence}

Douglas L. Brockmeyer, Department of Neurosurgery, Primary Children's Medical Center, 100 N. Mario Capecchi Dr., Salt Lake City, UT 84113. email: douglas.brockmeyer@hsc.utah.edu. 